\title{
Repercussões da experiência artística frente ao sofrimento psíquico grave, ao internamento e à exclusão social*
}

\section{Ana Paula Vicente de Oliveira ${ }^{1,2}$ \\ (D) https://orcid.org/0000-0001-9770-153X \\ Maria Inês Badaró Moreira ${ }^{1,3,4}$ \\ (D) https://orcid.org/0000-0001-5798-2023}

\footnotetext{
* A publicação deste artigo na Série Temática "Recursos Humanos em Saúde e Enfermagem" se insere na atividade 2.2 do Termo de Referência 2 do Plano de Trabalho do Centro Colaborador da OPAS/OMS para o Desenvolvimento da Pesquisa em Enfermagem, Brasil. Artigo extraído da dissertação de mestrado "Entre loucuras: discutindo a transformação do olhar de artistas criadores do espetáculo 'Projeto Bispo: tratados como bicho, comportam-se como um'", apresentada à Universidade Federal de São Paulo, Santos, SP, Brasil.

Universidade Federal de São Paulo, Santos, SP, Brasil.

2 Universidade Federal de São Paulo, Laboratório de Produção de Conhecimento Compartilhado em Saúde Mental, Baixada Santista, Santos, SP, Brasil.

${ }^{3}$ Universidade Federal de São Paulo, Departamento de Políticas Públicas e Saúde Coletiva, Baixada Santista, Santos, SP, Brasil.

${ }^{4}$ Universidade Federal de São Paulo, Coordenação do Curso de Psicologia, Baixada Santista, Santos, SP, Brasil.
}

Objetivo: analisar a elaboração de novas perspectivas pelos atores-criadores de Projeto Bispo: tratados como bicho, comportam-se como um sobre o sofrimento psíquico grave, o internamento e a exclusão social. Método: tratase de pesquisa qualitativa em saúde que associou pesquisa bibliográfica, trabalho de campo e entrevistas semiestruturadas desenvolvidas e aplicadas pela pesquisadora. Sete artistas foram entrevistados entre junho e agosto de 2018. No tratamento das entrevistas, seguiu-se a análise de conteúdo com a técnica de análise temática. Resultados: o estudo revelou que $O$ Coletivo operou experimentação na qual os artistas participaram do levantamento do material teórico que serviu de base às discussões estéticas, realizaram exploração do espaço urbano, fabricaram figurinos e objetos cênicos e elaboraram narrativas a partir das atividades coletivas. O encontro entre artistas e indivíduos em situação de rua, que perderam seu lugar social, sobretudo, devido ao uso de álcool e outras drogas, possibilitou a apropriação dessa temática no espetáculo. Conclusão: além da transformação da perspectiva dos artistas, a dramaturgia empreendida pelo grupo de teatro trouxe a percepção de que é possível provocar a formação de novas concepções e discursos a respeito do sofrimento psíquico severo, do internamento e da exclusão social por meio da arte.

Descritores: Saúde Mental; Arte; Transtornos Mentais; Desinstitucionalização; Marginalização Social.

\section{Como citar este artigo}

Oliveira APV, Moreira MIB. Repercussions of the Artistic Experience in the face of Severe Psychic Suffering, Internment and Social Exclusion. SMAD, Rev Eletrônica Saúde Mental Álcool Drog. 2021 jul-set.;17(3):47-56. doi: https://dx.doi.org/10.11606/issn.1806-6976.smad.2021.170011 


\section{Repercussions of the Artistic Experience in the face of Severe Psychic Suffering, Internment and Social Exclusion}

Objective: to analyze the elaboration of new perspectives by actors-creators of Projeto Bispo: treated like animals, behaving as one on severe psychic suffering, internment and social exclusion. Method: it is a qualitative research in health that associated bibliographic research, fieldwork and semi-structured interviews developed and applied by this researcher. Seven artists were interviewed between June and August 2018. Content analysis with the thematic analysis technique was followed for treating the interviews. Results: the study revealed that $O$ Coletivo operated an experiment in which the artists participated in the survey of theoretical material that served as a basis for aesthetic discussions, carried out exploration of urban space, manufactured costumes and scenic objects and elaborated narratives from the collective activities. The encounter among street artists and individuals, who lost their social place mainly due to the use of alcohol and other drugs, allowed this theme to be appropriated by the show. Conclusion: the analysis showed that, beyond the transformation of the perspective of actors-creators, the dramaturgy undertaken by the theater group brought the perception that it is possible to provoke the formation of new concepts and discourses about severe psychic suffering, hospitalization and social exclusion through the art.

Descriptors: Salud Mental; Arte; Trastornos Mentales; Desinstituticionalización; Marginación Social.

\section{Repercusiones de la experiencia artística ante el sufrimiento psíquico severo, internamiento y exclusión social}

Objetivo: analizar la elaboración de nuevas perspectivas por parte de actores-creadores del Projeto Bispo: tratados como animales, se comportan como tal sobre sufrimiento psíquico severo, internamiento y exclusión social. Método: es una investigación cualitativa en salud que asoció investigación bibliográfica, trabajo de campo y entrevistas semi estructuradas desarrolladas y aplicadas por esta investigadora. Siete artistas fueron entrevistados entre junio y agosto de 2018. Para el tratamiento de las entrevistas, se procedió a un análisis de contenido con la técnica de análisis temática. Resultados: el estudio reveló que $O$ Coletivo realizó un experimento donde artistas participaron del estudio del material teórico que sirvió de base para discusiones estéticas, llevaron a cabo exploración del espacio urbano, fabricaron trajes y objetos escénicos y elaboraron narrativas a partir de actividades colectivas desarrolladas. El encuentro entre artistas e individuos que perdieron su lugar social debido principalmente al uso de alcohol y otras drogas, permitió que este tema fuera apropiado en el espectáculo. Conclusión: El análisis mostró que, además de la transformación de perspectiva de actores-creadores, la dramaturgia emprendida por el grupo de teatro trajo la percepción de que es posible provocar la formación de nuevas concepciones y discursos sobre el sufrimiento psicológico severo, la hospitalización y exclusión social a través del arte.

Descriptors: Mental Health; Art; Mental Disorders; Deinstitutionalization; Social Marginalization. 


\section{Introdução}

Nas décadas de 1970 e 1980, as críticas capitaneadas pelo movimento de Reforma Psiquiátrica no Brasil ao paradigma psiquiátrico e ao dispositivo asilar se deram no sentido da conquista de um modelo de atenção psicossocial com vistas a produzir cuidado territorial e comunitário e novas formas de inclusão social de pessoas em sofrimento mental severo ou em situação de vulnerabilidade psicossocial. Por intermédio de ações concretas dos trabalhadores da saúde mental e a construção de uma Rede de Atenção Psicossocial ampla, buscou-se garantir um lugar social para esses sujeitos considerados "loucos"(1-5). Essa perspectiva singular favoreceu a construção de identidades e assegurou a consolidação de direitos e condições de despontar a cidadania antes improvável em ambientes de asilamento e exclusão.

Sob esse aspecto, experimentos estéticos e culturais que abordam questões referentes à saúde mental têm revelado diferentes discursos e práticas sobre a "loucura" e a diversidade, provocando alterações na percepção frente à diferença através do deslocamento da concepção de doença mental, a qual pressupõe que os sujeitos são incapazes de trocas sociais, para o conceito de experiências de diversidade psíquica ${ }^{(6-7)}$.

Desse modo, projetos artístico-culturais apresentaram-se como um dispositivo não institucional que fomenta a descoberta e a expansão de potencialidades, estimulando a autonomia e a criação de novas formas de inclusão social de pessoas com transtornos mentais ou em situação de vulnerabilidade psicossocial(1-5,8). Dentre os vários tipos de expressão artística, apropriamo-nos de elaborações das artes cênicas para compor este trabalho, considerando sua potência criativa e seu aspecto político de transformação.

O presente artigo é resultado da pesquisa que buscou analisar a transformação da perspectiva de atores-criadores $^{(9)}$ do espetáculo Projeto Bispo: tratados como bicho, comportam-se como um acerca de questões relativas ao campo da saúde mental, em sua trajetória de 2012 a 2015. Tal proposição artística pertencente à cena teatral contemporânea foi concebida e apresentada por o Coletivo, grupo que teve como propósito a elaboração de uma obra cênica que se distanciasse do espaço convencional do teatro e da arte institucionalizada e que funcionasse como instrumento estético e político de discussão crítica da realidade brasileira, além de retratar experiências análogas às vivenciadas pelos atorescriadores e pelo público(10-11).

As pesquisas e experimentações de O Coletivo orientaram-se pelo processo colaborativo, metodologia de criação e reflexão em que os artistas realizam uma produção cuja autoria é compartilhada por todos ${ }^{(10-11)}$.
Na primeira reunião do grupo, formado por artistas entre 18 e 35 anos, decidiu-se pelo levantamento sobre a biografia de Arthur Bispo do Rosário e sobre questões relativas à saúde mental. Os artistas definiram como território para o trabalho de campo a região do Centro Histórico de Santos/SP, área circunvizinha à Vila do Teatro (ocupação artística que abrigou O Coletivo). A partir do reconhecimento do território foram delineadas as primeiras experimentações do grupo, que tiveram periodicidade semanal. Nota-se neste ponto que a presença de pessoas que viviam em situação de vulnerabilidade social e psíquica no entorno da Vila do Teatro mudou radicalmente o rumo imaginado para o espetáculo. A percepção da correspondência existente entre a exclusão de pessoas com sofrimento psíquico grave e a marginalização de pessoas em situação de rua levou os atores-criadores a incorporarem ao processo criativo algumas questões referentes a essa parcela da população. O processo colaborativo de Projeto Bispo: tratados como bicho, comportam-se como um durou um ano e dois meses até a estreia do espetáculo, em julho de 2013.

A montagem final da encenação contava com dois atos distintos: a rua, composta por atores-criadores que expunham, dentre outras questões, a vulnerabilidade psicossocial e o uso abusivo de substâncias psicotrópicas; e o manicômio, no qual os artistas e o público eram levados à experiência do enclausuramento no interior da Casa da Frontaria Azulejada (edifício histórico situado em Santos/SP). Desse modo, a concepção artística efetivada por este grupo revelou diferentes aspectos do sofrimento psíquico que encontram-se imbricados por questões sociais, políticas e culturais de nosso tempo.

Na primeira pesquisa cênica do Coletivo pretendeu-se criar um espetáculo que articulasse a criação coletiva em processo à experiência social daqueles considerados "loucos", diferentes e excluídos, por meio de uma experimentação estética e política fundamentada no trabalho de campo e na investigação teórica sobre a loucura, o internamento e a exclusão(12-13).

O propósito do grupo era possibilitar que a encenação representasse uma ferramenta capaz de contribuir para o fortalecimento e a visibilidade da luta antimanicomial, além de colaborar com a transformação da perspectiva sobre a pessoa com sofrimento psíquico grave. Desta forma, acreditava-se que o modo de fazer e sua concepção artística operassem no sentido de tornar pública determinada conjuntura política, econômica e cultural do campo da saúde mental.

Tendo em vista o exposto, este artigo teve por objetivo analisar a possibilidade de expressões culturais e artísticas constituírem novas concepções sobre o sofrimento psíquico grave, o internamento e a exclusão social. Assim, a partir de experimentações realizadas durante o processo colaborativo do espetáculo Projeto 
Bispo: tratados como bicho, comportam-se como um, buscou-se analisar a percepção dos atores-criadores frente à produção desta intervenção artística e seus efeitos na reflexão sobre loucura, internamento e exclusão social conformados pelo paradigma psiquiátrico hegemônico.

\section{Método}

Este trabalho foi submetido à avaliação pelo Comitê de Ética e Pesquisa em Seres Humanos da Universidade Federal de São Paulo - CAEE: 02623218.1.0000.5505, tendo sido aprovado sob n'o 3.200.786.

$\mathrm{Na}$ busca por uma investigação que privilegiasse a perspectiva dos artistas do grupo $O$ Coletivo sobre os temas: "loucura", internamento e exclusão, optou-se pela pesquisa qualitativa em saúde, método de análise que abrange valores culturais de grupos e indivíduos, as inter-relações e processos históricos e sociais ${ }^{(14-15)}$. O caminho metodológico percorrido associou levantamento bibliográfico, trabalho de campo e realização de entrevistas semi estruturadas desenvolvidas e aplicadas por esta pesquisadora. As entrevistas foram realizadas entre junho e agosto de 2018 no Centro Cultural Cadeia Velha (Santos/ SP), sede do Movimento Teatral da Baixada Santista.

No primeiro momento, realizou-se revisão bibliográfica em busca de apropriação teórica referente aos temas "loucura", internamento e exclusão social. Para tanto, utilizou-se como referencial teórico o pensamento de Michel Foucault(16-19), Robert Castel(20) e Erving Goffman ${ }^{(21)}$. Foram revisados escritos de Franco Basaglia(22) e Franco Rotelli(23) com o propósito de resgatar o movimento de desinstitucionalização e a desconstrução dos saberes sobre a "loucura". Do mesmo modo, cumpriu-se a leitura de textos produzidos por autores envolvidos com a transformação ocorrida na cidade de Santos/SP em 1989 por ocasião da intervenção da Casa de Saúde Anchieta, que deflagrou uma relação intensa do transtorno mental com a cidade por meio de serviços de saúde territoriais e comunitários ${ }^{(24-25)}$. Foram consultadas referências sobre a Reforma Psiquiátrica(26-28), a fim de situar a experiência regional onde foi encenado o espetáculo.

$\mathrm{Na}$ fase relativa ao trabalho de campo, utilizou-se as técnicas de Observação Participante e registros em Diário de Campo. Houve aproximação gradual junto aos artistas que participaram da montagem, refletida de acordo com a recepção e compreensão de seus cotidianos. A princípio, realizou-se abordagem individual, que viabilizou a apresentação da proposta de estudo aos artistas e o convite para a participação na pesquisa. As abordagens ocorreram em atividades específicas do Movimento Teatral da Baixada Santista, como o Festival Santista de Teatro (FESTA) e o Festival de Cenas Teatrais (FESCETE). Deste modo, realizou-se aproximação mais efetiva junto ao elenco de $O$ Coletivo, a fim de analisar sua característica dinâmica de interação social(14-15,29).
Os participantes foram convidados a colaborar com o estudo de acordo com os seguintes critérios de inclusão: ser maior de 18 anos; ter experimentado envolvimento no processo colaborativo do espetáculo e atuado em ao menos três apresentações do mesmo; e ter concordado em colaborar com o trabalho por meio da assinatura do Termo de Consentimento Livre e Esclarecido - TCLE, conforme indicação do Comitê de Ética em Pesquisa para pesquisas envolvendo seres humanos. Os critérios de exclusão foram: não ter participado do processo de pesquisa e criação do espetáculo e/ou ter participado de apenas duas apresentações do mesmo. Dessa forma, sete artistas foram selecionados para este estudo.

Para as entrevistas semiestruturadas foi elaborado um roteiro com quatro questões norteadoras: 1) 0 que o(a) motivou a participar do Núcleo de Pesquisa Dramatúrgica Bispo do Rosário?; 2) O que pensava sobre o sofrimento psíquico grave, o internamento e a exclusão social antes do processo criativo do espetáculo?; 3) Como foi realizado o processo colaborativo de criação da montagem?; e 4) Qual sua perspectiva atual sobre o sofrimento psíquico grave, o internamento e a exclusão social? Realizou-se apenas uma entrevista com cada artista, que foi gravada utilizando um gravador de áudio com a permissão do mesmo. As entrevistas duraram em média uma hora cada.

Para o tratamento do material das entrevistas, seguiu-se a Análise de Conteúdo Temática(14), operacionalizada nas seguintes fases: iniciou-se com a ordenação das informações, apoiada pelas transcrições das entrevistas, leitura e organização do material de acordo com a base teórica adotada para esta pesquisa e por meio da identificação de temas centrais, tais como "loucura", internamento e exclusão social, estes considerados antes e depois do processo de criação do espetáculo. Posteriormente verificou-se a etapa de exploração do material, com leitura de recortes e fragmentos das falas dos entrevistados. Dessa maneira, foi realizada leitura flutuante de todo o material transcrito, de modo a estabelecer uma relação entre o objetivo desta pesquisa e os dados das entrevistas; por fim, passou-se à fase de tratamento dos resultados obtidos e a interpretação se deu com aproximação destes recortes com o referencial teórico constituído anteriormente, transcendendo os significados apresentados no material ${ }^{(14)}$.

A fim de assegurar o anonimato, os artistas foram identificados com a palavra "entrevistado", seguida de números que indicam a ordem em que as entrevistas aparecem no texto (Entrevistado 1 a Entrevistado 7).

\section{Resultados e Discussão}

A indagação que introduziu as entrevistas buscou esquadrinhar a motivação que levou cada um dos artistas a se aproximar do Núcleo de Pesquisa Dramatúrgica Bispo 
do Rosário. Desejava-se examinar se havia intenção por parte dos encenadores em realizar uma pesquisa dramatúrgica sobre questões referentes à "loucura" e à exclusão social ou se o interesse centrava apenas na atuação de um espetáculo, qualquer que fosse seu tema.

Os depoimentos revelaram que o principal impulso para a aproximação do grupo foi a disposição por um estudo sobre o sofrimento psíquico severo e a exclusão social no interior de um coletivo teatral. A problematização de questões familiares relacionadas a transtornos mentais e a identificação entre artistas e "loucos" ou marginalizados, considerando a situação-limite que ocupam na sociedade, também foram apontadas como estímulo à participação no processo colaborativo de criação(6).

A segunda questão apresentada durante as entrevistas tratou do encontro com o sofrimento psíquico anterior ao processo de criação da montagem. O intuito desse item foi investigar as experiências e concepções iniciais desses sujeitos com relação ao sofrimento psíquico grave, ao internamento e à exclusão social. Os depoimentos dos artistas revelaram que, na maior parte dos casos, o sofrimento psíquico próprio ou na família nortearam suas primeiras percepções. Foram relatados eventos como internação de parentes e uso abusivo de álcool e outras drogas.

Os participantes extrapolaram o objeto inicial do tópico e abordaram em suas declarações temas como: as relações entre transtorno mental e religiosidade, homossexualidade e exclusão social e a falta de respeito com a diferença remetidas principalmente às vivências à margem da sociedade ${ }^{(30)}$. Cabe ressaltar que os entrevistados disseram perceber o "Iouco" como alguém incapaz de integrar-se à sociedade ou mesmo uma pessoa estranha, diferente e enigmática, como explicitado pela literatura ${ }^{(16-17)}$; eles demonstram conhecimento a respeito do papel de controle social e moral desempenhado no interior dos hospitais psiquiátricos. Decerto, as condutas repressivas praticadas nas instituições asilares em nome da ordem social advém da apropriação da loucura como produto sócio-histórico e do lugar do "louco" como elemento desviante e a-social(16-20).

A terceira parte da entrevista, que versou sobre a experimentação realizada durante o processo coletivo de criação de Projeto Bispo, mostrou-se relevante no sentido de compreender o movimento que levou o grupo do preliminar estudo sobre a biografia de Bispo do Rosário à montagem de um espetáculo que debateu, dentre outros temas, a "loucura", o internamento e o contexto social da cidade de Santos no que tange à saúde mental e à população marginalizada.

O diretor de $O$ Coletivo declarou que a escolha pela representação da figura de Arthur Bispo do Rosário se deu pela observação de sua trajetória de vida entre indigência, sofrimento psíquico e internamento em instituições manicomiais( ${ }^{(31)}$, temas que o artista desejava expor em sua proposição artística. Em suas palavras: De início, tínhamos que descobrir o Bispo de cada um: o que nos incomodava, sufocava, qual era nosso grito, e em paralelo pesquisávamos sobre histórias reais que nos cruzavam [...]. E aí a gente começou a ir pra rua e aí a gente começou a ter contato total com as pessoas em situação de rua. Isso foi marcante pro espetáculo em si, né? Porque a gente começou a reconhecer o Bispo naquelas pessoas também (Entrevistado 1).

Segundo o diretor, tratava-se de encontrar aspectos dos atores-criadores ${ }^{(9)}$, como também da população em situação de vulnerabilidade e risco psicossocial confluente com a construção das personagens que remontassem à condição vivida por Bispo e tantos outros artistas considerados "loucos". O artista também enfatizou que, na fase do espetáculo que se passava dentro da Casa da Frontaria Azulejada, a "loucura" institucionalizada remontava aos hospitais psiquiátricos de outrora, notadamente a Casa de Saúde Anchieta, instituição que sofreu intervenção municipal em 1989(24-25). De fato, a experiência ocorrida em Santos foi o projeto mais radical de declínio de um manicômio como lugar de violência e exclusão social no Brasil, notório principalmente por ter inaugurado um novo tipo de cuidado comunitário em saúde mental articulado em ampla rede de apoio psicossocial(26-27). Conforme abordado pela literatura, as instituições psiquiátricas infligiam aos seus internos regras rígidas de comportamento e seu modo de operar dava-se principalmente pelo impedimento de relação social com o mundo externo(21). O manicômio, como instituição total, foi representado como lugar onde prevaleceu a violência, os maus-tratos, a tortura e o aniquilamento da individualidade e da liberdade ${ }^{(21-23)}$.

Ao versar sobre a criação de seu personagem, o entrevistado 2 lembrou-se de como desenvolveu algumas características consideradas peculiares ao transtorno mental. Sua narrativa remeteu à repressão moral sofrida pelos "loucos" que, enclausurados em hospitais psiquiátricos, acabavam por perder sua autonomia e identidade. Por certo, a perda da liberdade do internado atuava como dispositivo que sustentava seu aniquilamento e sua mortificação(21). Nessa perspectiva, ao tratar da condição do internado, seu personagem retomou as questões da apreensão e da vida no espaço fechado dos manicômios para denunciar o autoritarismo e os limites impostos aos internos pelo saber psiquiátrico(21-23).

O entrevistado 3, por sua vez, discorreu a respeito do processo colaborativo de criação que problematizou modos de ser e de estar no espaço social e espelhou algumas contradições da sociedade brasileira ${ }^{(13)}$. 0 artista destacou certos aspectos da produção artística, como constatado em seu depoimento: $O$ processo foi o seguinte: como primeiro criar? [...] A nossa pesquisa era essa: levar, apresentar durante $o$ 
processo performances sobre um processo de loucura, de alguém que enlouqueceu e o que essa pessoa traria enquanto conteúdo para colaborar na história do espetáculo que a gente queria contar. Que viés ali da vida do Bispo a gente poderia contar, não é? [...] Então eu optei não por uma loucura, mas por uma pessoa que vai esquecendo quem ela é. No meio daquele processo de situação de rua, não se sabe como ele chegou ali. [...] Ele começa a falar coisas que estão na cabeça dele; são memórias, frases desconexas. [...] Mas dentro disso, há muita sabedoria também (Entrevistado 3).

Ao caracterizar seu personagem, o ator buscou representar aspectos relativos a um saber oculto pertencente à loucura, que surge em oposição à sua face considerada obscura e amedrontadora. Como visto na literatura, tal enfoque foi historicamente difundido pelas artes, que muitas vezes retratou a loucura como uma experiência associada à animalidade e ao quimérico, exercendo fascínio por representar sua natureza oculta(16-18)

A entrevistada 4, por seu lado, enfatizou que as pesquisas feitas pelos atores a respeito das biografias de artistas considerados loucos, assim como as observações e a interação com as pessoas em situação de rua foram essenciais à construção dos personagens. A atriz relatou: [...] Eu mesma fui criando com o que eu via na rua, né? Muita fala minha também foi baseada na Stela do Patrocínio. [...] A elaboração do figurino também, foi na rua que eu peguei. Eu troquei roupa na rua com as pessoas, tirei minha roupa e elas me deram as delas, enfim. Eu encontrava na rua, lavava... e fui compondo assim mesmo (Entrevistada 4).

A artista realçou que muitos elementos observados nas relações sociais e nas imagens pitorescas do território compuseram a representação de sua personagem(13). Deste modo, seu depoimento foi ao encontro da literatura ao afirmar que a população em situação de rua sofre preconceito por não ter acesso ao asseio e outras necessidades básicas e, particularmente, por viver em meio à violência ${ }^{(30)}$.

O personagem criado pelo entrevistado 5 apresentou como característica principal o comportamento semelhante ao de um cachorro. O artista pretendeu representar a animalidade que por vezes é atribuída equivocadamente às demonstrações de raiva apresentadas pelos loucos. Nesse sentido, a analogia entre "loucura" e brutalidade exaltada pelo ator retratou a valorização moral que pressupõe a monstruosidade e a agressividade como condições para o internamento desses sujeitos ${ }^{(16-19)}$. Dentre outras construções, ele abordou a questão da plasticidade gerada pela intervenção artística, a qual teria sido provocada pelas pesquisas do grupo a respeito do sofrimento psíquico grave e da exclusão psicossocial.

Ao compor seu papel, o entrevistado 6 representou sobre os trejeitos produzidos por pessoas com sofrimento psíquico severo. Sua interpretação baseava-se especialmente em aspectos relativos à institucionalização da "loucura" e à padronização de comportamentos comuns diante do isolamento e abandono no interior dos hospitais psiquiátricos(21-23). Nas palavras do ator: Me inspirei em algumas coisas que eu via pra compor o personagem. [...] alguns gestos, eu procurei copiar, levar pra personagem, pra que ficasse mais crível, e, paralelamente a isso, o estudo da biografia do Bispo do Rosário também me ajudou a equilibrar [...] essas coisas. (Entrevistado 6).

O entrevistado 7, por seu turno, descreveu o personagem de sua autoria como sendo um jovem que faz uso abusivo de substâncias psicoativas. O artista revelou que, em algumas apresentações, o público evitou aproximar-se da estação cênica onde ele se encontrava ao vê-lo com um cachimbo de crack na mão. O fato de não ter sido reconhecido como integrante do espetáculo levou o ator a perceber a marginalização e a discriminação sofridas por pessoas em situação de vulnerabilidade psicossocial e por jovens vulneráveis a comportamentos de risco, especialmente aqueles indivíduos com problemas relacionados ao consumo excessivo de álcool e outras drogas $^{(30,32-33)}$. Seus comentários mostraram-se coerentes com a literatura ao enfatizar que há estigma social atribuído a essa população e uma difícil compreensão sobre o fenômeno das drogas ${ }^{(34)}$. Em suas palavras: [...] o espetáculo falava diretamente sobre aquelas pessoas. Aquelas pessoas que vivem nas ruas, nas margens escondidas da cidade: a travesti, o bêbado, o louco, o usuário de crack... e todos eles moram ali, naquele cenário, naquele local. (Entrevistado 7).

Segundo o ator, no cotidiano das grandes cidades, diferentes tipos de pessoas são destinados à exclusão social, e não somente os considerados como "loucos". Existem importantes dificuldades na sociedade contemporânea em reconhecer o diferente do convencional, ou normal, favorecendo a discriminação e exclusão social(28).

Observou-se que, no processo colaborativo de criação desenvolvido por O Coletivo, houve organização dos trabalhos por meio de estudos teóricos e pesquisas de campo que levaram à aproximação junto a pessoas em situação de rua e excluídos da sociedade(12). A inclusão da temática relativa a essa população no espetáculo deveu-se à percepção da analogia existente entre a exclusão social do "louco" e a marginalização de pessoas em situação de vulnerabilidade psicossocial. Sob esse aspecto, os artistas entenderam que o sofrimento psíquico severo é fruto do processo de marginalização e exclusão social, como elucidado pela literatura(28).

Para contextualizar as intervenções públicas, os procedimentos adotados pelo Coletivo incluíram exploração do espaço urbano como campo de experimentação

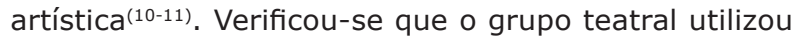
como dispositivo cênico as observações de imagens e relações sociais que sensibilizaram os integrantes na fase 
de elaboração de cenas no território. Para a elaboração dos figurinos e da caracterização dos personagens, houve empenho dos artistas no sentido de compreender o gestual, a vestimenta e o comportamento atribuído socialmente ao "louco" e às pessoas marginalizadas. As experiências e as memórias dos encenadores também constituíram material para a construção do espetáculo, como preconizado pelo processo colaborativo de criação(10).

$\mathrm{Na}$ obra final de O Coletivo, a questão do sofrimento psíquico e seus desdobramentos - internamento, exclusão e marginalidade - estavam presentes nos textos, figurinos e espaços cênicos. Desse modo, o espetáculo processou uma série de pequenas intervenções que transportaram os espectadores e os próprios artistas a uma dinâmica de reflexão, não apenas sobre o conjunto integral da montagem, mas sobre suas experiências pessoais e o sofrimento psíquico.

Ao final das entrevistas, os artistas discorreram sobre a transformação de suas perspectivas pela prática da criação e encenação de Projeto Bispo. A entrevistada 4 considerou significativo o refinamento de sua percepção sobre o sofrimento psíquico severo e o internamento durante o processo colaborativo de criação. Nas palavras da artista: [...] conhecendo a realidade a fundo através desse espetáculo, [...] eu vi que, realmente, é uma violência, né? Uma violência contra as pessoas e contra a própria loucura. É... tratar as pessoas como bicho, sendo que existe outra possibilidade que não de isolar, de prender, maltratar, enfim. [...] Existem outros métodos que eu acho que seriam mais eficazes, como a interação dessas pessoas com a natureza... quanto mais livres eles pudessem ser, entende? Melhor seria o tratamento. Prender a loucura é matar o ser humano. [...] Acho mais louco mesmo as pessoas que tentam ser normais o tempo todo (Entrevistada 4).

A atriz concluiu seu depoimento relatando que ampliou suas percepções a respeito do internamento e das práticas de maus-tratos e segregação para com a população em situação de rua e em uso de substâncias psicoativas; do mesmo modo, considerou que um possível modo de cuidar desses indivíduos deveria avaliar possibilidades de formar pessoas que se reconhecem como sujeitos de direitos e cidadãos plenos de valor social(22-23). Segundo preconizou a literatura, esse reconhecimento derivaria de uma prática contra a objetificação e a estigmatização, indicando a importância de sua relação com o meio social(23).

Em sua passagem por 0 Coletivo, o entrevistado 7 conheceu as atrocidades cometidas contra os pacientes psiquiátricos, assim como a realidade vivida por pessoas que fazem uso abusivo de substâncias psicotrópicas. 0 ator disse ter percebido que a loucura é provocada pelo imperativo de regras e padrões morais pela sociedade ${ }^{(18)}$.

Após ter relatado suas experiências pessoais e familiares com relação ao sofrimento psíquico grave, o entrevistado 6 expôs seu atual ponto de vista sobre o internamento e a loucura: [...] é lógico que essa questão da reclusão asilar dos manicômios, eu não concordo de forma nenhuma. Porque, na verdade, eu acho que mais atrapalha do que auxilia o paciente, né? Pra quem tem um familiar nessa situação... é difícil. Por isso o processo do Projeto Bispo trouxe muita vivência pessoal, né? (Entrevistado 6).

O artista referiu-se ao tratamento dado aos pacientes nos hospitais psiquiátricos e à criação de terapêuticas alternativas ao internamento. Ele destacou ainda a necessidade de ressocialização das pessoas em sofrimento psíquico. De fato, a inclusão social desses sujeitos possibilita a garantia dos direitos de cidadania, viabilizando a desinstitucionalização e possibilitando o acesso desses usuários a serviços da rede de atenção em saúde mental(28).

Ao encerrar sua reflexão sobre pessoas em situação de vulnerabilidade psicossocial, o entrevistado 5 explicitou: Por mais que antes do espetáculo, por exemplo, eu tivesse bem propenso a ser um colaborador das causas de pessoas fragilizadas, de deficientes intelectuais, [...] depois do espetáculo se potencializa isso. (Entrevistado 5).

Seu depoimento ilustra a conotação negativa dada à "loucura" e à diferença, apontando que trata-se de uma questão cultural que refere-se apenas àqueles que são considerados diferentes, como evidenciado pela literatura(17-18).

Já o entrevistado 2 concluiu sua declaração pontuando que seu interesse pelo transtorno mental vinha desde o final da adolescência, período em que ele conseguiu sobrepujar o medo que sentia de pessoas em sofrimento psíquico. O artista comentou: [...] quando eu comecei a quebrar esses medos, do padrão do que é ser louco, eu comecei a me interessar. Eu acho que o teatro teve uma importância aí, nessa curiosidade em saber o que era "louco", né? (Entrevistado 2).

O diretor do espetáculo, por sua vez, entendeu que a "loucura" é um processo de adoecimento característico de nossa sociedade, ou seja, uma sociedade embasada em princípios e regras que direcionam a um tipo de vida anônimo, impessoal e conformista(28). Ele afirmou: [...] se não surta, a pessoa deprime. Adoece! A gente vive numa sociedade doente (Entrevistado 1).

Em seu testemunho, ele salientou o avanço na quantidade de diagnósticos relativos ao sofrimento psíquico, que indicam a problemática vivida principalmente nas grandes cidades. Também mencionou suas percepções com relação às reações provocadas no público pela intervenção artística. Segundo o diretor, [...] o trabalho toca aquelas pessoas de alguma forma [...] Não é aquele teatro passivo que você chega, apaga a luz e você tá protegido com aquela quarta parede.[...] Não, você tá ali vivendo junto, cê tá no processo, cê tá nas mesmas emoções. [...] Você faz parte daquilo, né? [...] É um teatro que te provoca, [...] enfim. Então é uma peça que tá aí, urgente! (Entrevistado 1). 
De acordo com o diretor teatral, a emergência da intervenção artística ocorreu pelo desejo de afetar e ser afetado pela realidade social do diferente e do excluído ${ }^{(12)}$.

Por fim, o entrevistado 3 expressou suas considerações sobre a participação no processo colaborativo da encenação: [...] é preciso um olhar com empatia, um olhar real sobre o outro. Não é possível excluir um ser humano da sociedade porque ele nasceu com tal e tal característica. [...] Sabemos que vivemos numa sociedade extremamente higienista. Então a gente tá aqui pra denunciar. [...] Isso foi uma coisa que esse processo de trabalho nos deu: essa abertura de pensamento. Perceber que a gente precisa e pode se quiser - é uma questão de predisposição também - fazer alguma coisa pra além da arte (Entrevistado 3).

A narrativa do ator foi ao encontro da literatura ao assumir perspectivas exteriores ao paradigma psiquiátrico e às normas impostas pela sociedade(19). Desse modo, o processo criativo possibilitou aos artistas e ao público adquirir uma percepção que provocou diferentes maneiras de pensar e [inter]agir com outros campos da experiência humana(35).

Ao final das entrevistas, foram unânimes as constatações dos artistas com relação às mudanças de suas concepções relativas à loucura, ao internamento e à exclusão após o processo colaborativo de criação do referido projeto artístico. Constatou-se que a prática artística convergiu para a exploração daquilo que lhe era exterior, buscando operar no limite da linguagem artística e explorando sua analogia com a "loucura"(6). $\mathrm{Na}$ maior parte das declarações, o sofrimento psíquico manifestou-se intrinsecamente relacionado ao contexto social em que vivem.

\section{Considerações Finais}

Este estudo teve como objetivo analisar a possível mudança de perspectiva sobre o sofrimento psíquico e sobre questões relativas ao campo da saúde mental por meio da intervenção teatral. A pesquisa evidenciou que, para além da transformação da percepção, o processo colaborativo de criação do espetáculo Projeto Bispo: tratados como bicho, comportam-se como um trouxe a compreensão aos artistas de que é possível provocar a elaboração de diferentes concepções e discursos a respeito do sofrimento psíquico grave, do internamento e da exclusão social por meio da criação artística.

Os resultados revelaram que o grupo de teatro operou uma experimentação na qual os atores-criadores, antes de chegarem à encenação, participaram do levantamento do material teórico que serviu de base às discussões estéticas, realizaram exploração do espaço urbano para formação das primeiras representações fundamentadas nas observações das imagens e das relações sociais do território, fabricaram os figurinos e os objetos cênicos utilizados na montagem e elaboraram as narrativas a partir das atividades coletivas desenvolvidas.

Ademais, a pesquisa de campo realizada pelos atores-criadores possibilitou o encontro com indivíduos em situação de rua que perderam seu lugar social devido sobretudo ao uso de álcool e outras drogas. Nesse sentido, o vínculo criado entre artistas e moradores de rua permitiu que houvesse a apropriação dessa temática no espetáculo, considerando a correspondência existente entre a exclusão da pessoa em sofrimento psíquico severo e a marginalização de pessoas em situação de vulnerabilidade psicossocial.

De fato, podemos afirmar que a dramaturgia empreendida por $O$ Coletivo provocou uma dinâmica em que os artistas encontraram-se implicados com a obra cênica como um todo, promovendo, assim, a transformação de suas perspectivas com relação ao transtorno mental, ao internamento e à exclusão social que confrontou a ótica do paradigma psiquiátrico hegemônico.

Finalizamos reiterando que este estudo tencionou refletir criticamente sobre questões relativas à saúde mental, conforme preconizado pela Reforma Psiquiátrica. Sob esse aspecto, ao problematizar estigmas e visar a transformação social, o espetáculo Projeto Bispo: tratados como bicho, comportam-se como um contribuiu para a denúncia e a desconstrução de preconceitos pelos atores e discriminação frente ao sofrimento psíquico grave e às pessoas em situação de vulnerabilidade psicossocial.

É importante relevar que a pesquisa buscou aprofundar as perspectivas dos encenadores em seu contexto sócio-histórico. Sendo assim, entende-se que são necessárias novas pesquisas a respeito de intervenções artísticas constituídas na interface com a saúde mental que possam abranger o ponto de vista de artistas de outras localidades, bem como de outros campos das artes.

\section{Agradecimentos}

Aos artistas de $O$ Coletivo pela colaboração na fase de coleta de dados.

\section{Referências}

1. Amarante P, Torre EHG. "Back to the city, Mr. citizen!" - psychiatric reform and social participation: from institutional isolation to the anti-asylum movement. Rev Adm Pública. 2018;52(6):1090-107. doi: https://doi. org/10.1590/0034-761220170130

2. Amarante P, Torre EHG. Madness and cultural diversity: innovation and rupture in experiences of art and culture from Psychiatric Reform and the field of Mental Health in Brazil. Interface (Botucatu). 2017;21(630):763-74 doi: https://doi.org/10.1590/1807-57622016.0881 
3. Amarante P, Freitas F, Pande MR, Nabuco E. The artisticcultural field in Brazilian psychiatric reform: the identity paradigm of recognition. Salud Colectiva. [Internet]. 2013 [cited 2019 Dec 10];9(3):287-99. Available from: http://www.scielo.org.ar/scielo.php?script=sci_ arttext\&pid=S1851-82652013000300002\&Ing=es

4. Lancetti A. Saúde-loucura n07: saúde mental e saúde da família. 3a. ed. São Paulo: Hucitec; 2007. 188 p.

5. Oliveira M. The construction of participatory policies in the comprehensive care of users of alcohol and other drugs. SMAD, Rev Eletronica Saúde Mental Alcool Drog. [Internet]. 2019 [cited Jan 13 2020];15(4):1-2. Available from: http://revistas.usp.br/smad/article/view/163927 6. Lima EMFA, Pelbart PP. Art, medical treatment and insanity: a territory in flux. Hist Cienc Saude-Manguinhos. 2007;14(3):709-35. doi: https://doi.org/10.1590/ S0104-59702007000300003

7. Lima EMFA. For a minor art: resonances between art, clinical practice and madness nowadays. Interface. (Botucatu). 2006;10(20):317-29. doi: https://doi. org/10.1590/S1414-32832006000200004

8. Nicácio F, Campos G. The complexity of crisis care: contributions of deinstitutionalization to the creation of innovative practices in mental health. Rev Ter Ocup Univ São Paulo. [Internet]. 2004 [cited 2020 Jun 17];15(2):7181. Available from: http://www.revistas.usp.br/rto/article/ view/13942

9. Maia R. O ator criador. 2a ed. São Paulo (SP): Galpão do Folias; 2005. 105 p.

10. Araújo A. O processo colaborativo no Teatro da Vertigem. Sala Preta. [Internet]. 2006 [Acesso $13 \mathrm{dez}$ 2019];6:127-33. Disponível em: http://www.revistas. usp.br/salapreta/article/view/57302

11. Abreu LA. Processo colaborativo: relato e reflexões sobre uma experiência de criação. Cad ELT. [Internet]. 2003 [Acesso 3 jan 2020];1(2):33-41. Disponível em: http://www2.eca.usp.br/bctb/obra.php?cod=16334

12. Fernandes S. Performativity and Genesis of the Scene. Rev Bras Est Pres. (Porto Alegre) [Internet]. 2013 [cited 2019 Dec 3];3(2):404-19. Available from: http://www. seer.ufrgs.br/presenca

13. Fernandes $S$, organizador. Teatro da Vertigem. Rio de Janeiro: Cobogó; 2018. 336 p.

14. Minayo MCS. Ciência, técnica e arte: o desafio da pesquisa social. In: Minayo MCS, organizador. Pesquisa social: teoria, método e criatividade. 21. ed. Petrópolis: Vozes; 2002. p. 9-29.

15. Minayo MCS. O desafio do conhecimento: pesquisa qualitativa em saúde. 14. ed. São Paulo: Hucitec; 2014. $416 \mathrm{p}$.

16. Foucault M. Doença Mental e Psicologia. 2. ed. Lisboa: Texto \& Grafia; 2008. 103 p.

17. Foucault M. História da Loucura na Idade Média. 10. ed. São Paulo: Perspectiva; 2014. 551 p.
18. Foucault M. A Loucura Só Existe em uma Sociedade. In: Motta MB, organizador. Ditos e Escritos: Problematização do Sujeito - psicologia, psiquiatria e psicanálise. Vol. 1. 3. ed. Rio de Janeiro: Forense Universitária; 2014. p. 162-4.

19. Foucault M. O poder psiquiátrico: curso no Collège de France (1973-1974). 2. ed. São Paulo: Martins Fontes; 2012. $511 \mathrm{p}$.

20. Castel R. A ordem psiquiátrica: a idade de ouro do alienismo. Rio de Janeiro: Graal; 1978. 329 p.

21. Goffman E. Manicômios, prisões e conventos. 9. ed. São Paulo: Perspectiva; 2015. 312 p.

22. Basaglia F. Escritos Selecionados em saúde mental e reforma psiquiátrica. Rio de Janeiro: Garamond; 2010. $331 \mathrm{p}$.

23. Rotelli F. A instituição inventada. In: Rotelli F, Leonardis O, Mauri D, organizadores. Desinstitucionalização. São Paulo: Hucitec; 2001. p. 89-100.

24. Kinoshita RT. Em busca da cidadania. In: Campos FCCB, Henrinque CMP, organizadores. Contra a maré à beira-mar: a experiência do SUS em Santos. São Paulo: Hucitec; 1997. p. 67-77.

25. Kinoshita RT. Saúde Mental e a Antipsiquiatria em Santos: vinte anos depois. Cad Bras Saúde Mental. [Internet]. 2009 [Acesso 4 dez 2019];1(1):1-8. Disponível em: https://periodicos.ufsc.br/index.php/cbsm/article/ view/68443/41222

26. Pitta AMF. An assessment of Brazilian psychiatric reform: institutions, actors and policies. Ciênc Saúde Coletiva. 2011;16(12):4579-89. doi: https://doi. org/10.1590/S1413-81232011001300002

27. Amarante P. Apresentação. In: Basaglia F. Escritos selecionados em saúde mental e reforma psiquiátrica. Rio de Janeiro: Garamond; 2010. p. 7-15.

28. Amarante $P$, Carvalho AL, Uhr B, Andrade EA, Moreira MCN, Souza WF. Loucos pela vida: a trajetória da reforma psiquiátrica no Brasil. 20. ed. Rio de Janeiro: FIOCRUZ; 2016. $136 \mathrm{p}$.

29. Cruz O Neto. O trabalho de campo como descoberta e criação. In: Minayo MCS, organizador. Pesquisa Social: teoria, método e criatividade. 21. ed. Petrópolis: Vozes; 2002. p. 51-66.

30. Cervieri N, Uliana C, Aratani N, Fiorin P, Giacon B. Access to health services from the perspective of homeless people. SMAD, Rev Eletrônica Saúde Mental Álcool Drog. [Internet]. 2019 [cited Jan 13 2020];15(4):1-8 Available from: http://www.revistas.usp.br/smad/article/ view/164014

31. Hidalgo L. O Senhor do Labirinto. Rio de Janeiro: Ed. Rocco; 1996. 192 p.

32. Camargo E, Gonçalves J, Felipe A, Fava S, Zago M, Dázio $E$. Drug use and abuse among university students and interface with public policies. SMAD, Rev Eletrônica Saúde Mental Álcool Drog. [Internet]. 2019 [cited Feb 
13 2020];15(4):1-8. Available from: http://www.revistas. usp.br/smad/article/view/163950

33. Tibiriçá V, Luchini E, Almeida C. Drug users' perspective on their treatment and the psychosocial care network. SMAD, Rev Eletrônica Saúde Mental Álcool Drog. [Internet]. 2019 [cited Feb 15 2020];15(4):1-8. Available from: http://www.revistas.usp.br/smad/article/ view/164013

34. Marchetti S, Saeki T. Social inclusion of drug users at a Service of Psychosocial Attention and Care to alcohol and drug addiction in a city in the State of São Paulo. SMAD, Rev Eletrônica Saúde Mental Álcool Drog. [Internet]. 2019 [cited Feb 15 2020];15(4):1-8. Available from: http:// www.revistas.usp.br/smad/article/view/163956

35. Providello GGD, Yasui S. Madness in Foucault: art and madness, madness and unreason. Hist Cienc SaúdeManguinhos. 2013;20(4):1515-29. doi: https://doi. org/10.1590/S0104-59702013000500005

\section{Contribuição dos Autores}

Concepção e desenho da pesquisa: Ana Paula Vicente de Oliveira, Maria Inês Badaró Moreira. Obtenção de dados: Ana Paula Vicente de Oliveira. Análise e interpretação dos dados: Ana Paula Vicente de Oliveira, Maria Inês Badaró Moreira. Redação do manuscrito: Ana Paula Vicente de Oliveira, Maria Inês Badaró Moreira. Revisão crítica do manuscrito quanto ao conteúdo intelectual importante: Ana Paula Vicente de Oliveira, Maria Inês Badaró Moreira. Orientadora de pesquisa originária da dissertação de mestrado da primeira autora: Maria Inês Badaró Moreira.

Todos os autores aprovaram a versão final do texto. Conflito de interesse: os autores declararam que não há conflito de interesse. 